\title{
An analysis on Investment and Financing Mode of China- Myanmar Railway project under the Background of "One Belt, One Road"
}

\author{
Xiaoyu Chen \\ International Business School \\ Yunnan University of Finance and Economics \\ Kunming, China \\ 278983107@qq.com \\ Ersi Liu* \\ International Business School \\ Yunnan University of Finance and Economics \\ Kunming, China \\ liuersi309@126.com
}

\author{
Wenhong Shen \\ International Business School \\ Yunnan University of Finance and Economics \\ Kunming, China \\ 993777342@qq.com \\ Ke Yan \\ International Business School \\ Yunnan University of Finance and Economics \\ Kunming, China \\ 543487184@qq.com
}

\begin{abstract}
One belt, one road" strategy has accelerated the pace of opening to South Asia and Southeast Asia. Transportation infrastructure construction is the priority development area of this strategy. However, Myanmar is a "crossroads" which links China, South Asia and Southeast Asia together, it is also a pair of wings to China open to South Asia and Southeast Asia. Yunnan Province, which is next with Myanmar, as a bridge head in the southwest area in China, has a huge investment opportunity of transportation infrastructure. However, it is crucial to choose a suitable investment and financing Mode, because China- Myanmar Railway project is so big that requires huge capital investment, at the same time, Myanmar's political situation is unstable. Only the investor selects an appropriate investment and financing mode, can reduce the risk of the project.
\end{abstract}

Keywords-"One belt, one road"; China-Myanmar Railway; Investment and financing mode.

\section{INTRODUCTION}

Domestic and foreign scholars on the research of the transportation infrastructure investment and financing mainly concentrated in the investment subject, financing channels, financing model, etc.

In recent years, adapted to the reality of China, the economics profession to infrastructure investment and financing research mainly concentrated in the capital gap and system aspects. In general, these studies have the following several aspects:

a) review of traditional financing system.

b) classification and review of the existing financing

c) the exploration of innovation of the financing system.

\footnotetext{
* Corresponding author
}

According to the present problems in infrastructure finance system, the research of traffic infrastructure finance system innovation made in-depth discussion, thought the financing subject and financing diversification are the important tasks in the new period financial system reform. Yang pointed out that solving the problem of transport infrastructure development backward and funding gap, the government should transform investment and financing methods, and use of market mechanisms to mobilize private capital and foreign capital into the infrastructure field [1]. Yu analyzed the way of private capital into urban infrastructure franchising and service contract [2]. In addition, Chinese scholars also has carried on the research of urban infrastructure of equity financing funds, local government bonds, the infrastructure industry, PFI financing modes, etc. [3-4].

In recent years, Project Financing in the infrastructure financing has played a more and more important role.,it rised in the late $1970 \mathrm{~s}$. Sun and Xing Compared with the traditional financing mode, it can more effectively solve the problem of large infrastructure construction project funds, and it is applied by more and more countries[5].

Now about the research of project financing is relatively rich, all kinds of project financing modes of research are very informative. Some scholars of highway, port and other specific project financing should pay attention to the problems and corresponding countermeasures put forward various views[67]. Dai points out that BOT is an emerging mode in last decade in the world, is the use of foreign capital and private capital to build the infrastructure of a new mode of financing. [8]It caused the wide attention of international finance. Liu studied on the necessity of project financing of BOT. Zhao compared the advantages and disadvantages and applicable scope between BOT and TOT, and puts forward a mix form called TBT which is the better way of the current large-scale transportation infrastructure project financing [9]. Ye, Ma and 
Wang contrast the franchise and ABS, and according to the national conditions elaborates the advantages and disadvantages of different modes, it puts forward that ABS would get a greater development in China [10].

Throughout the development of the theory, we can see all kinds of scholars did much research on the investment and financing of infrastructure project from different angles and depths, has already formed the situation of schools of thought contend and complex , and had a rich achievement, but there are obvious shortcomings. Especially for infrastructure investment and financing mode selection mechanism, the relationship between the nature of Infrastructure project and project investment and financing mode, and matching relationship between the value of infrastructure project and project investment and financing mode lack in-depth research.

\section{THE IMPORTANCE FOR YUNNAN TO INVEST IN MYANMAR'S INFRASTRUCTURE}

\section{A. The position of Yunnan province in the strategy of "One belt, one road"}

"One belt, one road" (B\&R) is short for "21st Century Maritime Silk Road" and "Silk Road Economic Belt". It is an innovation for China to transfer capacity advantage, technical and financial advantages, experiences and mode advantages into marketing and cooperation advantages. It provides new opportunities for the western region in China. Yunnan, as an important bridgehead for China opening South Asia, which has obvious geographical advantages. It is connected to the Silk Road economic zone in the north, the south connects the Maritime Silk Road. It is the only province of Chinese communicates with South and Southeast Asia by land, and connects Europe and Africa from the Middle East. Playing regional advantages, promoting international transport corridor construction with neighboring countries, constructing economic cooperation of Mekong Sub-region, and building radiation center for South and Southeast Asia are the positioning of Yunnan in the strategic of B\&R.

\section{B. The Strategic Position of Myanmar's transportation}

Myanmar is the southern neighbor of China, which connects India in the west and neighbors Bangladesh. The south of Myanmar connects Andaman Sea. The east neighbors Thailand and Laos. Myanmar is located in the "crossroads" that communicated by China, Southeast Asian and South Asian. And it occupies an important strategic position. Myanmar has abundant natural resources and developing urgent desire. It is seen as "the last piece of Asian investment hot spot." The Construction of China-Myanmar Economic Corridor will encourage China to expand foreign investment, to achieve diversification energy strategy in economic; in politics, the construction of China-Myanmar economic corridor is the westward strategy of China. Chinese westward strategy includes two directions: one is from the northwest into the Central Asia, and then towards the Middle East and Europe; the second is to enter the South Asia from the southwest, and then connect the Indian Ocean Rim region and West Africa [11]. Therefore, in the sense of strategy, Myanmar is a plat.

\section{THE OPPORTUNITY FOR YUNNAN TO INVEST IN MYANMAR'S RAILWAY INFRASTRUCTURE}

In China, the old saying goes: "To rich, build roads first". The scheme of Construction of transportation network between China and Eurasia represents this simple philosophy. In construction of $\mathrm{B} \& \mathrm{R}$, transportation is the priority development areas. Therefore China try its full best to construct transportation infrastructure, such as Trans-Asian Railway and Kunming-Bangkok highway. Since Yunnan has an important region advantage, the construction and operation of transport infrastructure between China and Myanmar will help Yunnan promote the transport sector do out of China on a larger scale and a higher level. According to the data of Myanmar Ministry of Commerce, up to the year of 2014, a total length of railway is $4000 \mathrm{kms}$ in Myanmar [12].But it the lacks of overall planning and has low service competitiveness. Most of the new railway lines locate in the mountains, which has high construction costs. And the remaining funds for the maintenance and improvement of existing core railway network is limited. All of these result in poor railway network status.

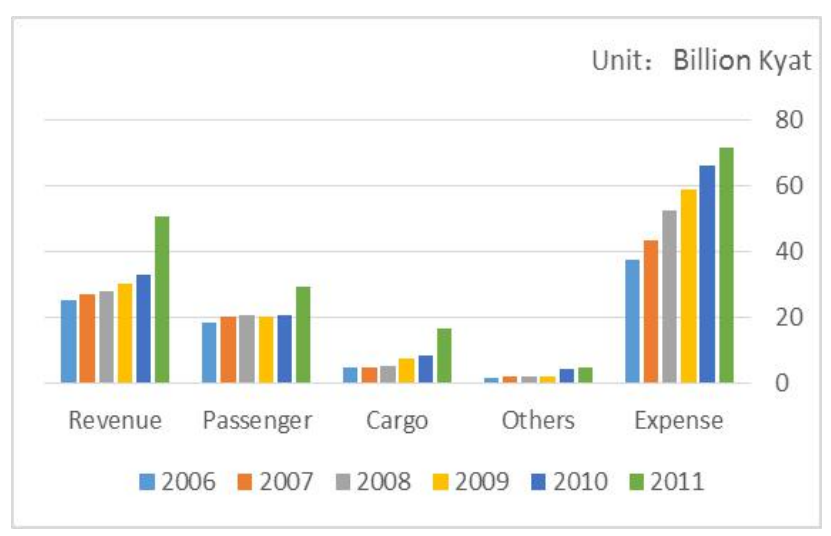

Fig. 1. From 2006 to 2011, the comparison of financial situation of Myanmar's Railway

According to financial situation from 2006 to 2011 showed that, revenues in the rail sector just half of the cost [13]. Financial resources put into the construction of new railway lines which have high cost and low return, limiting the capital investment for core railway network. But the core railway network is pot of growth income in the future. On the other hand, the total revenue of rail transport growth year by year. After the year of 2008, with the aid of the developed countries to Myanmar, the railway transport developed rapidly. More and more residents of Myanmar selected railway transport. Because of fast speed, adaptability, large transport capacity and low-cost, railway transportation is slowly being accepted by the people of Myanmar. Thus, under the background of B\&R, it has brought new opportunities for Yunnan to invest in Myanmar's railway. 


\section{THE ALTERNATIVE INVESTMENT AND FINANCING MODEL FOR YUNNAN TO INVEST MYANMAR'S RAILWAY INFRASTRUCTURE}

\section{A. Commercial Loans}

Commercial loans are the financing model that transport infrastructure projects usually adopt. Based on commercial loans' unique business or government bank credit qualifications and sufficient financial situation, it takes loan from the State Development Bank or commercial bank. But at the same time, long-term loans is limited by the size of state loans. And debt management that make joint venture railway companies and rail investment companies difficult to operate, insolvency is a serious problem as well. Under the background of B\&R, financing international loans may also be adopted by Yunnan to invest transport infrastructure in Myanmar, which have low interest rates, long repayment period and other characteristics. There exists currency risk and limited foreign investment, if take loans from the World Bank, the Asian Development Bank and the Asian infrastructure investment bank.

\section{B. Bond Financing}

Issuing infrastructure bond is a way of financing directly from community by utilizing corporation or government credit. Compared with the banking market, the advantages of issuing bonds lie in higher interest rates than bank deposits. For utilizing funds, issuing bonds has more autonomy than bank funds. Which can determine the duration of the bond according to the needs of funds operation. It can quickly raise funds for urban infrastructure. But, Myanmar capital market has many shortcomings, such as immature capital market, high-risk of issuing bonds, many restrictions and raising funds with limited.

\section{BOT}

BOT (Build-Operate-Transfer), it refers to the government grants the private sector (including foreign companies) a franchise contract by a certain period, licenses its financing construction and the operation of particular public infrastructure, and allows it to pay off the loans, to recycle investment, to make profits by charging from user or selling products; at the expiration of the concession period, the infrastructure will be transferred to the Government free of charge.

BOT projects have huge amount of investment funds and long period of recycling capital. The main risk is relatively concentrated and shared by equity investors and debt investors. BOT projects introduced private capital, reducing the finance expenditure of the project. Therefore BOT model is suitable for large-scale infrastructure projects, such as railways, highways. The number of fast food demand in the train is great, if the train snacks maintain the original price, then there will be competitive and not conducive to obtain excess profits. In this situation, in order to obtain extra profits and run the train safely and stably, the train operator will increase the price of products. In general, fast-food is daily consumer goods which lacks of elasticity of demand, but on the train, it will become a flexible rarities, therefore the price changes will greatly affect passengers' demand for fast food. As prices increase slowly, low-income passengers will start to reduce the demand of fast food. The higher the price of train snack; the less the demand of train meal until it reaches the equilibrium of supply and demand, thus the price of fast food on the train is much higher than in market. Meanwhile the choice of fast food in train is generally those with higher income or middle-income groups.

\section{BOOT}

BOOT(build-own-operate-transfer) is a derivative mode of BOT. Private partners or an international consortium by financing for infrastructure construction, after the completion of the project, has the ownership of the project and operation. After the expiration of a certain time, transfer the ownership and management of the project to the government. As you can see, compared with BOT, there are two advantages of using the BOOT mode: One is the ownership. After the completion of the project, within the prescribed time limit, not only have the project management, also has its ownership. The second point is handed over to the right time will be longer. From the completion of the project to be handed over to the government of time, the transfer time of BOOT is usually longer than BOT [14].

BOOT (Build-Operate-Transfer) model has a complex structure, whose basic idea shown in Fig. 2.

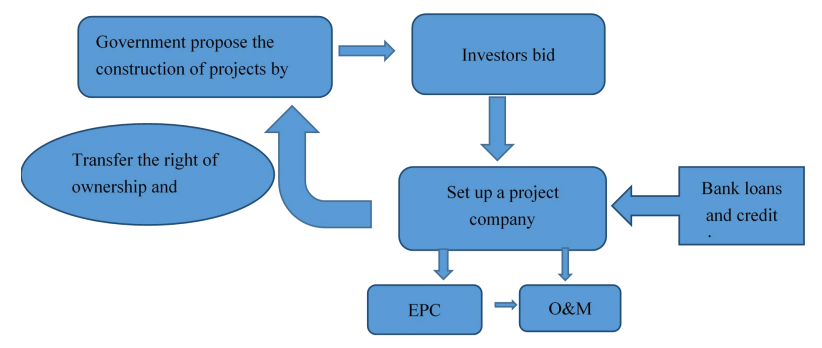

Fig. 2. The framework of BOOT project

BOOT and BOT are equally applicable to large-scale infrastructure projects. But adopting the BOOT mode, within the prescribed period, the enterprise has the ownership after completion of the project. As a result, the BOOT mode is more suitable for large cross-border infrastructure project which has weak economic and unstable politics than the BOT mode.

\section{THE DECISION ANALYSIS OF INVESTMENT AND FINANCING MODE OF CHINA- MYANMAR RAILWAY CONSTRUCTION PROJECT}

Kunming, China and Myanmar-Kyaukpyu railway project is part of the Trans-Asian Railway Network, including Kunming-Ruili section $(690 \mathrm{~km})$ in China and MuseKyaukpyu $(810 \mathrm{~km})$ in Myanmar. China- Myanmar Railway is a huge project with broader sectors, long-term period, large amount of investment capital. Because of instability political situation in Myanmar and lacking of management experience about large construction projects such as high standard railway investment and construction, the government or business as the main financing for the project has a certain difficulty. Therefore, in order for the smooth implementation of the China- Myanmar railway projects in Myanmar, it is advised 
for the project to adopt investment and financing of BOOT. The best way is to establish the project company by China and Myanmar, which controlled by the Chinese capital and take loans from the World Bank, the Asian Development Bank and other policy banks or commercial bank. And the project company will select a contractor to design and construct. After the completion of the project, have the ownership and the right to operate in a certain period of time. By the expiration, the project company will transfer the right of ownership and management to Myanmar government.

China-Myanmar railway project belongs to cross-border projects, which adopt investment and financing of BOOT for two favorable factors: On the one hand, Myanmar's government will get the ultimate ownership of the rail project with no money or very little money. The commercial risks of financing, construction, operation and maintenance will be taken by the project company. That decentralized government investment risks, relived the financial burden of the government and improved the efficiency of project construction and operation. Since foreign investors introduced new technologies, it is in favor of the Government of Myanmar to improve and enhance the management level of the project. On the other hand, it reduced some of the political risks for Chinese investors. The project company will be able to enjoy preferential loans, tax incentives that made by government and the relevant departments, which create a certain profitability criteria.

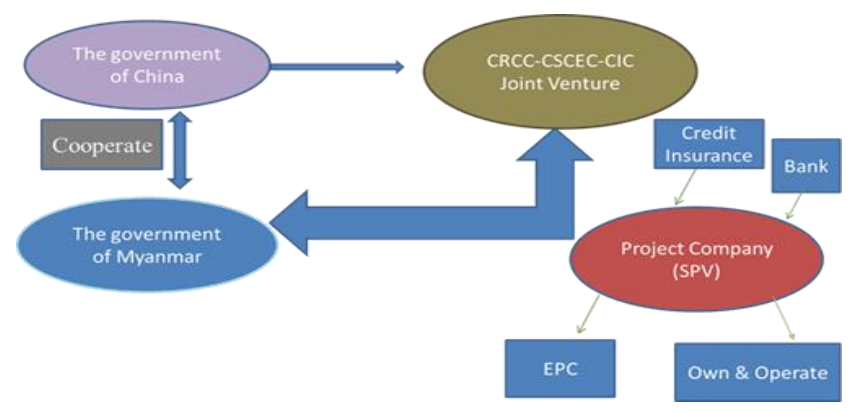

Fig.3. The relation of BOOT of China- Myanmar Railway Project

There are some problems, when adopt financing mode of BOOT. Investors of BOOT projects in the contract period cannot just give up or transfer investment funds. And the investment cycle is too long; the amount of funds is large; the project will be influenced by the Myanmar's economy in operating processing. What's more, investors and lenders have too large risks. It is necessary to analyze and evaluate returns on investment and to adopt prevention measures to reduce the risk while Yunnan investing China- Myanmar Railway construction project.

\section{CONCLUSION}

China makes efforts to promote B\&R strategy to open South Asia and Southeast Asia. Under this background, Yunnan faces much opportunities to invest in Myanmar's transportation infrastructure, especial China- Myanmar Railway. However, there are some problems in ChinaMyanmar Railway construction project, such as it needs huge funds, challenges the instability of Myanmar's government and high transport costs. So to guarantee the project smoothly, the investor have to select an investment and financing mode which has enough ability to raise funds and reduce Myanmar's political risk. The Myanmar's government or business as the main financing for the project both has difficulties, because of its low level of economic development. Myanmar's capital market is still immature, is not suitable for the local capital markets. However, BOOT is suitable for a project which is large, wide-range, long-term and weaker country's project. BOOT can reduce some political risks, at the same time, investor enjoys preferential policies and certain profits. So, it is suggested that Yunnan choose BOOT to invest in ChinaMyanmar Railway construction project.

\section{ACKNOWLEDGMENT}

First of all, I would like to extend my sincere gratitude to my supervisor, Professor Liu, for his instructive advice and useful suggestions on my thesis. I am deeply grateful of his help in the completion of this thesis. Without his consistent and illuminating instruction, this thesis could not have reached its present form. Second, I would like to express my heartfelt gratitude to Shen and Yan, who have offered me valuable suggestions in the academic studies. Finally, I am also deeply indebted to all the other tutors and teachers in Management Studies for their direct and indirect help to me.

\section{REFERENCES}

[1] J. Yang, "On the Investment of Infrastructure," China Economic Publishing House, 2003, pp. 50-55

[2] C.M. Yu, "Urban infrastructure investment and financing," 1st ed., Chins Planning Press, 2004, pp. 104-119.

[3] J.L. Liu and X.G. Zeng, "On the Financing and the Profit Development for Urban Rail Transit," Urban Mass Transit, 2004,4, pp. 19.

[4] L.Y. Zhang and Q.S. Zhang, "Project Financing Decision-Making Model and Its Application in Financing of Expressway Project," Journal of Transportation Systems Engineering and Information Technology, 2006.

[5] C.L. Xing and X.B. Sun, "The investment of project financing structure choice," CO-Operative Economy \& Science, 2004, PP. 35-36.

[6] X. Yang, "Highway construction financing mode," Enterprise Reform and Management, 2006.

[7] H. Wang, "The Application of the Project-financing Mode in the Construction of the Port Infrastructure," Sci-Tech Information Development \& Economy, 2006.

[8] D.S. Dai, "Project Financing," 2nd ed., China Machine Press, 2004.

[9] Q. Zhao, "Based on the BOT and TOT infrastructure-TBT project financing mode," Construction market and bidding and tendering, 2006.

[10] C.Y. Ye, Z.P. Ma and Z.Y. Wang, "Application of the ABS Pattern to Project Financing in Enterprises in China," Contemporary Economy \& Management, 2006.

[11] G.S. Lu, "CIMB Economic Corridor: A new move to the west," World Affairs, 2013.

[12] James Lynch. "Myanmar's Transport Sector Assessment," International Reference Research, 2013.

[13] Asian Development Bank, "Myanmar: Transport Sector Initial Assessment ," 2012.

[14] H.Z. Wang, "A study on operation mode of the new China-Myanmar railway," Railway Transport and Economy, 2012, PP. 87. 